\title{
Simón Rodríguez y la educación republicana: relaciones entre el sur de Colombia-Túquerres y el norte de Ecuador-Latacunga
}

\author{
Carlos Augusto Paladines Escudero ${ }^{1}$ \\ Pontificia Universidad Católica del Ecuador PUCE, Ecuador
}

Recepción: $13 / 03 / 2020$

Evaluación: 18/03/2020

Aceptación: 01/04/2020

Artículo de Investigación-Reflexión

DOI: https://doi.org/10.22267/rhec.202525.82

\section{Resumen}

El objetivo de este artículo es analizar la relación entre Túquerres y Latacunga a partir de la acción y la teoría desplegada por Simón Rodríguez en uno y otro lugar durante la construcción de la República. A lo largo del texto se muestra la importancia asignada por Simón Rodríguez a la conformación de la República; se analizan los principales componentes de la educación republicana y su metodología de implementación, y finalmente, se aborda las relaciones de esta vasta región respecto del sistema de educación que se requiere en la actualidad.

Pocos proyectos educativos han resaltado tanto la profunda vinculación de la educación con la vida democrática y social como el de Simón Rodríguez; de ahí que comprender este modelo suponga examinar previamente su concepción de la sociedad americana, la misma que, a su criterio se presentaba marcada no solo por agudos conflictos nacionales sino ante todo por los de carácter social y por eso dividida por un nuevo género de dominadores y dominados. Sobre estas y otras categorías organiza Simón Rodríguez su plan de una 'educación republicana y social', como él mismo la denomina, y sobre la cual nos narra que hacía ya más de veinticuatro años que él venía hablando y escribiendo pública y privadamente, apoyándose en una fuerte crítica y ruptura con la educación tradicional o testamentaria e imprimiendo a su vez al proyecto un claro carácter alternativo. Es en la denuncia de un pasado heredado y vigente, así

1 Doctor en Filosofía. Grupo de investigación: Pensamiento Ecuatoriano. Línea de investigación: Pensamiento latinoamericano contemporáneo. Correo electrónico: capaladines@yahoo.es 
como en el anuncio de un porvenir por construir, como constituye el plan de una 'educación republicana y social', haciendo que una y otra fase del proyecto confluyesen como las dos caras de una misma moneda.

Palabras clave: educación republicana; educación social; Simón Rodríguez

\title{
Simón Rodríguez and the Republican education: the relationships between the south of Colombia - Túquerres and the north of Ecuador - Latacunga
}

\begin{abstract}
The objective of this article is to analyze the relationship between Túquerres and Latacunga from the action and theory deployed by Simón Rodríguez in both places during the construction of the Republic. Throughout the text, the importance assigned by Simón Rodríguez to the conformation of the Republic is shown; the main components of republican education and its implementation methodology are analyzed, and finally, the relations of this vast region regarding the education system required today are addressed.

Few educational projects have emphasized the profound link between education and democratic and social life as much as that of Simón Rodríguez; hence, understanding this model requires a prior examination of his conception of American society, which, in his opinion, was marked not only by acute national conflicts but, above all, by those of a social nature and therefore, divided by a new genre of dominators and dominated people. On these and other categories, Simón Rodríguez organizes his plan of a 'republican and social education', as he himself calls it, of which he had been speaking and writing publicly and privately for more than twenty-four years, based on a strong criticism and rupture with traditional or testamentary education and bringing at the same time a clear alternative character to the project. It is in the denunciation of an inherited and current past, as well as in the announcement of a future to be built, that he constitutes the plan of a 'republican and social education', making both phases of the project converging into two sides of the same coin.
\end{abstract}


Keywords: Republican education; social education; Simón Rodríguez.

\section{Simón Rodríguez e a educação Republicana: relações entre o sul da Colômbia-Túquerres e o norte do Equador-Latacunga}

\section{Resumo}

O objetivo deste artigo é analisar a relação entre Túquerres e Latacunga a partir da ação e da teoria implantada por Simón Rodríguez em um e outro lugar durante a construção da República. Ao longo do texto é evidenciada a importância atribuída por Simón Rodríguez à formação da República; São analisados os principais componentes da educação republicana e sua metodologia de implementação e, por fim, abordam-se as relações dessa vasta região com o sistema educacional que se exige atualmente.

Poucos projetos educacionais destacaram tanto o vínculo profundo entre a educação e a vida democrática e social quanto o de Simón Rodríguez; Portanto, compreender esse modelo significa examinar previamente sua concepção de sociedade americana, que, em sua opinião, foi marcada não apenas por agudos conflitos nacionais, mas sobretudo por aqueles de natureza social e, portanto, dividida por um novo gênero de dominadores e dominados. Sobre essas e outras categorias, Simón Rodríguez organiza seu plano de uma 'educação republicana e social', como ele mesmo a chama, sobre a qual nos conta que fazia quase vinte e quatro anos que falava e escrevia em público e em particular com uma crítica forte e rompimento com a educação tradicional ou testamentária e por sua vez dando ao projeto um caráter alternativo claro. É na denúncia de um passado herdado e atual, bem como no anúncio de um futuro a ser construído, que se constitui o projeto de uma 'educação republicana e social', fazendo convergir as duas fases do projeto como as duas faces do uma mesma moeda.

Palavras-chave: Educação republicana; Educação social; Simón Rodriguez. 


\section{Introducción}

Este trabajo analiza una de las coyunturas más importantes y conflictivas de la historia de del sur de Colombia y el norte de Ecuador. En aquel tiempo estos territorios estuvieron inmersos en procesos de carácter continental como fue el de ruptura y superación del sistema colonial, por un lado; y, por otro, inmersos en los primeros pasos para la conformación de una República: integrada en un comienzo por los países bolivarianos que se soñó agruparía a las seis naciones hispanoamericanas liberadas por Bolívar: Venezuela, Colombia, Ecuador, Panamá, Perú y Bolivia, proyecto éste que pronto abortó; posteriormente el sueño de gran parte de la élite política e intelectual de aquel entonces se orientó a constituir la Gran Colombia que para 1830 de igual modo fracasó; abriéndose paso finalmente la conformación de las actuales repúblicas de Venezuela, Colombia y Ecuador.

Entrando sin más en materia, ¿qué avatares vivió esta región, en aquella época? ¿qué Provincias/ Departamentos /Gobernaciones, Intendencias constituían una unidad en el ámbito productivo, en el de movilidad, en el arte, en las artesanías, en la administración política y de la justicia, ¿incluso en su topografía?

La división y separación, con todas sus consecuencias, entre el sur de Colombia y el norte del Ecuador se consolidó años después y dividió en dos a esta región que anteriormente era una.

En efecto, siglos y décadas antes, entre la región sur del Virreinato de Santafé y la sierra norte de la Audiencia de Quito se desplegaron vínculos y relaciones en todos los órdenes. Notables investigadores contemporáneos sobre la Audiencia de Quito informan sobre el floreciente comercio que desarrollaban algunas familias nobles, como el Marqués de Selva Alegre, el Conde de Casa Jijón. ${ }^{2}$ En el pasado Eugenio Espejo informó sobre los pueblos indígenas, particularmente sobre los indios de Alangasí que comerciaban con la provincia de Popayán, con respecto a la cual dice que "no existía desnivel en la balanza comercial sino más bien una pequeña

2 Ver: Christian Büschges, Familia, honor y poder. La nobleza quiteña de Quito en la época colonial tardía (1765-1822), (Quito: Trama, 2007), 112-119; Christiana Borchart de Moreno, "Llamas y ovejas: El desarrollo del ganado lanar en la Audiencia de Quito". En: Escobari de Querejazu, Laura -coord. Colonización agrícola y ganadera en América, siglos XVI-XVIII: su impacto en la población aborigen, (Quito: Ediciones Abya-Yala, 1995), 153-190. 
inclinación a favor de Quito: dos o tres mil pesos en monedas de oro por año". Otro rubro que vinculaba a Pasto con Quito fue la producción artesanal que atraía dinero, especialmente de la zona sur de Colombia. E. Espejo en el volumen dedicado a su obra educativa hace mención de Pasto en cinco ocasiones y en el volumen tercero de la edición crítica de sus escritos menciona a Pasto en ocho; en una de ellas habla de los "talentos ventajosos de los pastusos, morlacos, guayaquileños, panameños, que son dependientes de nuestra provincia". ${ }^{3}$

De igual modo, en aquella época, los vínculos económicos se vieron reforzados por el traslado del producto de las minas de oro y de plata, por lo recaudado en abundancia a través del Tributo de Indios y por los impuestos para la Real Corona que enviaba la Audiencia de Quito vía Pasto, Popayán, Santa Fe y Cartagena hacia España. Numerosos bienes comerciales transitaban a lomo de mula desde la sierra norte y central, incluido Esmeraldas, con el consiguiente desarrollo de la ganadería de las provincias del Carchi hasta Chimborazo, rumbo a los territorios de Pasto, Popayán, Bogotá y a través del Río Magdalena, algunos de ellos encontraban en Cartagena, Santa Marta y la Depresión de Monposina los puertos de salida de sus exportaciones hacia la Nueva España y hacia España como también el lugar de compra de los bienes importados que demandaba Quito de la Madre Patria y de Europa para su progreso.

Igualmente, el intercambio de la producción artística y musical en circulación en la segunda mitad del siglo XVIII, fue ámbito de relevancia para la Audiencia de Quito cuyos productos se comercializaban en un territorio muy amplio desde Cartagena hasta Arequipa. Algunas muestras del arte quiteño reposan en las iglesias y conventos de Pasto, Popayán y Santa Fe. ${ }^{4}$

Pero en aquella época no solo el sistema productivo del norte de Quito estaba imbricado con el del sur de la actual Colombia, igual o mayor era la vinculación administrativa y judicial entre la Audiencia de Quito y el Virreinato de Santafé o virreinato del Nuevo Reino de Granada (1717-1723, 1739-1810 y 1815-1819) que concentraba en su Capital las responsabilidades, la ejecución y el control de trámites administrativos como la nominación de

3 Astuto Philip L., (ed.), Eugenio de Santa Cruz y Espejo: obra educativa, (Caracas: Biblioteca de Ayacucho, 1981), 227.

4 Osvaldo Granda Paz, Pintor y soldado en la Independencia. Ecuador-Colombia, (Ed. Morada, 2017). 
autoridades dependientes de la Corona y de la Iglesia por el Real Patronato. La aplicación de las leyes que eran emitidas desde España y reclamaban su implementación, como la administración de la justicia obligaba a muchos quiteños a pasar por Pasto rumbo a Santafé para resolver los casos judiciales de última instancia. De igual modo, tuvo que compartir la Audiencia los gastos que demandaba la protección y la defensa del virreinato con las milicias armadas y los fuertes acantonados en Cartagena para proteger estos territorios de la piratería y el contrabando de los ingleses, etc.

La topografía en aquellos tiempos también coadyuvó a vincular a nuestros pueblos, ya que la Hoya Central Occidental del Guáitara, se halla cerrada al sur por el Nudo de Boliche y al norte por el de Pasto, correspondiéndole al Ecuador el espacio del valle del río Carchi, con sus afluentes los ríos Grande y Blanco que, apenas pasado el puente de Rumichaca, adopta en territorio colombiano el nombre de Guáitara o también río de Las Lajas. En igual forma, en el entorno de Tulcán se levanta un interesante grupo de volcanes, (el Chiles con $4.780 \mathrm{~m}$, el Cumbal, con $4.970 \mathrm{~m}$ y el Cerro Negro con $4.770 \mathrm{~m}$ ), parte ecuatorianos y parte colombianos porque la línea de frontera pasa por sus faldas. Al norte del Cumbal, la cordillera Occidental sigue pero ya en territorio colombiano y toma el nombre de páramo de Colimba, hasta la cercanía del Azufral de Túquerres que son las últimas montañas que se divisan desde Tulcán. ${ }^{5}$ Tal vez haya sido Eugenio Espejo, en 1780, en Marco Porcio Catón, en el acápite referente a Talentos Nacionales, quien mejor captó esa unidad o similitud no solo de la topografía que el callejón interandino presenta en esta región sino también de los pueblos y etnias que desde Otavalo, pasando por Tulcán, Túquerres y Pasto se extendía hasta Popayán. "Aunque el Reverendísimo Feijoo no probase la igualdad de naciones en orden al uso del discurso, la probarían, hasta la evidencia, los talentos ventajosos de los pastusos, morlacos, guayaquileños, panameños, que son dependientes de nuestra provincia y que son despreciados del vulgar Luciano". 6

Hasta las erupciones, terremotos y epidemias que afectaron a esta región dieron motivo a compartir los momentos de adversidad. Si los terremotos de 1746, 1755, 1757 y el de Cumaná de 1778 o las diversas erupciones del Cotopaxi: 1766 y 1768 y del Tungurahua: 1776 y 1781

5 Amílcar Tapia Tamayo, El pupo: visión histórica, (Tulcán: Ed. Parlamento Andino, 2003), 11-13.

${ }_{6}$ Astuto, Eugenio de Santa Cruz y Espejo: obra educativa, 227. 
afectaron a esta región, más grave fue el terremoto de 1797 que afectó de norte a sur, es decir, de Popayán a Loja, destruyendo muchas ciudades y villas y ocasionando varios miles de muertos, especialmente en la zona de Riobamba. ${ }^{7}$ Según un informe del Presidente Muñoz de Guzmán de 1797, se puede contabilizar un total de 12.553 personas a las que habría que añadir las que perecieron en poblados y lugares dispersos por lo que no sería exagerado afirmar que el número de muertos ascendiera a $16.000 .{ }^{8}$

Por supuesto, tampoco es comprensible el tiempo, el espacio, las personas y los recursos de estas regiones, que se vieron afectadas y sufrieron el rigor, la disminución demográfica, los gastos de guerra, el traslado del ejército libertador, la confrontación y hasta el enfrentamiento entre criollos y chapetones y entre quienes defendían la Corona y quienes lucharon por derrumbar al sistema colonial. Figura emblemática de este enfrentamiento en tierras de la actual Colombia y Ecuador fue Juan Agustín Agualongo Cisneros, quien ha sido rescatado por la actual historiografía en la grandeza y las limitaciones de su lucha. ${ }^{9}$

\section{Diálogo entre Túquerres-Colombia 1849-1851 y Latacunga-Ecuador 1843-1851}

No es propósito de este texto concentrar la atención en las vinculaciones que se establecieron entre diversos departamentos de la Gran Colombia, en aquellos tiempos, en cuanto al sistema productivo, al judicial y administrativo, al de intercambio comercial, ni resaltar el enfrentamiento en que se batieron los defensores del orden constituido y los detractores del mismo, en Quito, en la sangrienta represión y desangre que sufrieron los patriotas de parte del ejército español entre 1810 y 1812 hasta 1822 , o en

\footnotetext{
7 Ver: Teodoro Wolf, Crónica de los fenómenos volcánicos y terremotos en el Ecuador. Con algunas noticias sobre otros Países de la América Central y Meridional desde 1599 hasta 1797, (Quito: Imprenta de la Universidad Central, 1904), 120.

8 Ver: José Egred A. El terremoto de Riobamba de febrero de 1797, tomo 2, (Quito: Ed. Abya-Yala, 2000), 79.

9 Otros autores han realizado una exhaustiva investigación al respecto ver: Osvaldo Granda Paz, "Las primeras letras en Quito (1791-1850)", (Tesis de doctorado en Ciencias de la Educación, CADE Universidad de Nariño-RUDECOLOMBIA, 2014); Lydia Inés Muñoz Cordero. El Gobierno Autónomo de Quito en 1809, Repercusiones en la Independencia de la Nueva Granada, (Quito: Ed. Academia Nacional de Historia del Ecuador, 2018); Gerardo León Guerrero Vinueza, Pasto en la Guerra de la Independencia: 1809-1824, (Bogotá: Ed. Tecnimpresores, 1994), 195.
} 
Pasto cuando los realistas padecieron la arremetida del Ejército Libertador con el derramamiento de sangre a lo largo de más de una década: 1809-1824.

En esta ocasión el interés es resaltar el diálogo que emergió entre Túquerres y Latacunga en aquellos años, a partir de la acción y la teoría que Simón Rodríguez desplegó en uno y otro lugar para la construcción de la República, aspecto éste escasamente cubierto por la investigación, salvo excepciones que confirman la regla. ${ }^{10}$ Sin lugar a dudas, Simón Rodríguez fue figura clave en ambos procesos: el Independentista y el Republicano, pero especialmente en el segundo en que están aún empeñados nuestros pueblos. Desde aquel entonces, él no ha dejado de iluminar con sus reflexiones sobre lo que se requería para construir una República y hoy se requiere para mantenerla; es decir, disponer de una educación republicana.

El esquema de análisis busca en primer lugar, traer a la memoria la importancia asignada por Simón Rodríguez a la conformación de la República. No es comprensible la obra teórica y práctica del Maestro de Simón Bolívar sin esa voluntad primigenia por dar forma a una república, por crear, en palabras de Simón Rodríguez, un 'gobierno verdaderamente republicano'. En segundo lugar, se examinarán los principales componentes de una educación republicana y su metodología de implementación. La educación republicana, bautizada así por él, es a su criterio condición indispensable para mantener en pie tanto al Estado como a la República. Finalmente se abordará la problemática de las relaciones de esta vasta región en el actual escenario de la geopolítica mundial, en relación al sistema de educación que se requiere en la actualidad, tema éste por supuesto amplio y complejo. En esta ocasión solo se abordará la geopolítica a seguir en medio de los diferentes bloques regionales en curso a nivel mundial.

El análisis tiene como fuente una obra compuesta de dos capítulos: el uno fue un "Extracto sucinto sobre la educación republicana 1849, ${ }^{11}$ escrito para el Gobernador de la provincia de Túquerres, coronel Anselmo Pineda;

${ }^{10}$ Osvaldo Granda Paz, Las primeras letras en Quito (1791-1850), Osvaldo Granda Paz, "Antecedentes de la propuesta de educación popular de Don Simón Rodríguez", Revista Historia de la Educación Colombiana, 14 (14), (2011), 9-29. Disponible en: https://revistas.udenar.edu.co/index.php/rhec/article/view/564. Osvaldo Granda Paz, "Mora Berbeo y La Enseñanza Mutua En La Gran Colombia". Revista Historia de la Educación Colombiana 19(19), (2016), 81-105. Disponible en: https://doi.org/10.22267/ rhec.161919.16.

${ }^{11}$ Simón Rodríguez, "Extracto sucinto sobre la educación republicana", Neo-Granadino, Nos. 39, 40 y 42, Bogotá, mayo de 1849. 
y el otro, Consejos de amigo dados al colegio de Latacunga $1851,{ }^{12}$ a su Rector, don Rafael Quevedo. Con ambos trabajos se cierra la descomunal obra de Simón Rodríguez en educación, pues ambos fueron redactados pocos años antes de su muerte: 28 de febrero de 1854, a la edad de 84 años. Aproximadamente a mediados de 1846 el Maestro Rodríguez abandonó Latacunga, luego de una permanencia de tres años en Ecuador: seis meses en unas minas de sal del Gral. Juan José Flores en el litoral en miras a establecer un proyecto técnico industrial, y dos años y medio en Latacunga como se desprende de la correspondencia que mantuvo con el Obispo Torres, Roberto Ascázubi y José Ignacio París, de retorno de Túquerres al Ecuador. Al no poder continuar hacia Bogotá, debido al triunfo del general José Hilario López conocido anti bolivarista, partió hacia Guayaquil y luego hacia el Perú (1853). ${ }^{13}$

Ahora bien, ¿Por qué estos dos trabajos han resultado importantes no solo en cuanto a la producción de $\mathrm{S}$. Rodríguez sino también para el futuro de nuestras regiones y países? ¿Qué secretos encerró Rodríguez entre las líneas de estos textos? Bajo otro giro, ¿la educación republicana puede ser considerada como la columna vertebral que permitiría construir el templo que requería la Gran Colombia? ¿La educación republicana es una pilastra insoslayable para la vida en democracia?.

Por regla general, se ha convertido en un lugar común, en el discurso moderno e incluso en el contemporáneo, señalar el papel hegemónico de la educación para el desarrollo de los pueblos. Frecuentemente somos encandilados con frases como las siguientes: "solo la educación salvará al país", "la educación debe ser política prioritaria del Estado", "los países que han accedido al "desarrollo" lo han hecho porque supieron invertir en educación", "si no cambiamos la educación no va a cambiar el país", "la educación genera crecimiento económico", "países dominados por el analfabetismo no progresan. ${ }^{14}$

Sin lugar a dudas, estos eslóganes y su correspondiente discurso de exaltación de la educación son en parte correctos, tienen algo de verdad u

${ }^{12}$ Simón Rodríguez, "Consejos de amigo dados al colegio de Latacunga 1851", Obras Completas, tomo I, (Caracas: Ediciones Rectorado-Universidad Simón Rodríguez, 2016), 241.

${ }^{13}$ Rodríguez, Obras Completas, tomo I, 118.

${ }^{14}$ Conferencia desarrollada en la Universidad Politécnica Salesiana, mesa "La EDUCACIÓN COMO PARTE FUNDAMENTAL DEL DESARROLLO ECONÓMICO DEL ECUADOR”, QuiTo, 2004. 
objetividad, más en su exageración y exclusividad pueden resultar falsos. Tanto o más urgente e importante que el llamado a la promoción de la educación en general puede ser la necesidad de una Educación Republicana. Para ser exitosa la educación no solo debe apuntar a los beneficios o la utilidad que ella puede aportar a las personas, sino además contribuir, a criterio de S. Rodríguez, a la construcción de una nueva república.

Bajo la perspectiva, no de una educación en general sino de una educación especial: la educación republicana habrá que reasumir la lectura del "Extracto sucinto sobre educación republicana y los Consejos de amigo dados a un colegio de Latacunga, obras de compleja relectura, de no fácil interpretación, sea porque abrieron con una crítica o cuestionamiento a la educación colonial aún vigente en aquella época: educación colonial, educación privada y confesional, educación nacional, educación testamentaria en sus palabras, todas ellas caldo de cultivo y el alimento diario que mantenía a las nuevas repúblicas sometidas a los lazos coloniales que en diferentes ámbitos no acababan de romperse: piénsese en el sistema jurídico, en la administración centralizada, en la convivencia entre los poderes locales con los de las órdenes religiosas, en el sistema hacendario, en el campo abandonado y en las ciudades centros del "progreso".

\section{La propuesta de Simón Rodríguez: gobierno verdaderamente republicano}

En Sociedades Americanas 1828, -cuyo subtítulo es: cómo serán y cómo podrían ser en los siglos venideros. En esto han de pensar los americanos, no en pelear unos con otros- primera publicación que hizo a cinco años de su retorno de Europa, con lo que abrió las puertas a lo que vendría posteriormente, en la primera página advierte que:

El estado actual de la América pide serias reflexiones" -y que- "es un deber de todo ciudadano instruido el contribuir con sus luces a fundar el Estado, como con su persona y bienes a sostenerlo... la causa pública está en ocasión de hacer época, y esta es la de pensar en un GOBIERNO VERDADERAMENTE REPUBLICANO. La América es (en el día) el único lugar donde sea permitido establecerlo. ${ }^{15}$

${ }^{15}$ Simón Rodríguez, Sociedades Americanas, (Caracas: Biblioteca Ayacucho, 1990), 6-7. 
A comienzos de 1823, el Maestro del Libertador retornó a Cartagena, luego de un periplo de diecisiete años: 1806 a 1823 en que permaneció en Europa. Desde inicios de su retorno coadyuvó a que los pueblos hispanoamericanos conquisten la Independencia de España, etapa esta del proceso que tocó a su fin en la batalla de Ayacucho, diciembre de 1824, y permitió se abra una segunda etapa, la de construcción de las nuevas repúblicas, ésta también de carácter inédito y revolucionario. No había en el mundo de ese entonces, dominado por la monarquía, mayor experticia sobre la forma de construir repúblicas y habría de ser precisamente en este ámbito, el de levantar los cimientos y las principales columnas del edificio republicano en que el aporte de Rodríguez iba a traspasar las fronteras de tiempo e incluso mantener la actualidad y vigencia de sus reflexiones sobre lo que se requería y hoy se requiere para ser una República.

Simón Rodríguez fue uno de los que mejor visualizó y vislumbró los peligros de este enfrentamiento, las agitaciones que contra el gobierno desatarían las fuerzas conservadoras y especialmente los obispos y curas que no acababan de aceptar la ruptura con la Madre Patria. El pasado realista y la formación poco democrática de altos representantes del clero y de la oligarquía terrateniente que atentaban contra la educación republicana. ${ }^{16}$

Examinemos con mayor detenimiento algunos elementos de la propuesta de S. Rodríguez.

\subsection{El conflicto social}

Simón Rodríguez, fue de los pocos fundadores de nuestras repúblicas que entendieron que se había desatado un nuevo conflicto de carácter eminentemente social, pues había aparecido un nuevo 'sujeto histórico', inesperado e indeseable para muchos:

\footnotetext{
${ }^{16}$ El Gral. Antonio José de Sucre se expresaba del obispo de Quito, Leonardo Santander y Villavicencio en los siguientes términos: "este maldito Obispo, que ya me tiene quemada la sangre, y relacionado con todos los curas godos, puede mantener el país en agitación (...) siendo nuestro declarado enemigo (...) Yo no sé por qué, el Libertador me recomienda conservar a reformulación del seré tan loco que le sirva con un enemigo tan poderoso en nuestro seno, que mañana hace estrellar estas Provincias contra la República (...) No mantengo con este Obispo el menor resentimiento, porque particularmente, nada me ha hecho; pero tengo tal convencimiento de su maldad, que se me fuerza a vivir con él en Quito, no responderé del día en que lo tire por la escalera, por canalla. Ud. conoce que no soy exaltado, pero no puedo aguantarlo más". Citado por Jorge Núñez, "Inicios de la educación pública en el Ecuador (Estudios)", Procesos Revista ecuatoriana de historia, 13 (13), (2015), 3-23. DOI:10.29078/rp.vli13.329
} 
Se ha obtenido ya en América, -dirá-, no la Independencia, sino un armisticio en la guerra que ha de decidirla... El estado de la América no es el de la Independencia, sino el de una suspensión de armas -A su criterio- por poco que se observe la dirección que van tomando los negocios públicos en América, se advertirán muchas impropiedades, que arguyen un principio de desorden. ${ }^{17}$

Esta perspectiva le permitió ver y juzgar la complejidad del proceso de las guerras civiles, en que fueron tan pródigas nuestras repúblicas en sus primeras décadas de vida independiente.

De este modo, la temida "anarquía de los pueblos", el tiempo crítico de las rivalidades o revoluciones como solía denominar Rodríguez a esta etapa, y que se prolongó por muchos años en la mayoría de los países latinoamericanos, llegando en el caso ecuatoriano hasta bien avanzado el siglo XIX, la asumió nuestro autor a partir no tanto del carácter o sicología de nuestros indómitos o "revoltosos pueblos" o de sus bajos niveles de formación educativa, cuanto de las demandas y los reclamos que amplios sectores populares formulaban para la satisfacción de sus necesidades inmediatas e indispensables para vivir, y a partir de la frustración que la receta republicana ofrecía a sus aspiraciones en múltiples aspectos, particularmente en lo referente al mundo del trabajo. En palabras de Rodríguez:

No hay reunión de hombres sin un fin: el fin es satisfacer necesidades... Indispensables, Facticias o Ficticias. En las indispensables están: el alimento, el vestido... los animales nacen vestidos; el alojamiento, los animales se alojan a poca costa; la curación, los animales no se curan, y la distracción, ellos se distraen sin gastar. ${ }^{18}$

\subsection{La inestabilidad política}

Ha sido proverbial en la historiografía tradicional de nuestros países resaltar las innumerables desventajas que se tuvo que enfrentar al inicio de la vida republicana, derivadas de la inestabilidad política y la división

${ }^{17}$ Rodríguez, Sociedades Americanas, 19-20.

${ }^{18}$ Simón Rodríguez, Extracto sucinto de mi obra sobre la educación republicana, (Austin: Fondo Editorial J. A. Segrestáa, Universidad de Texas, 1969), 29. 
interna. ${ }^{19}$ En la primera mitad del siglo XIX se intensificaron los conflictos políticos y militares, internos y hasta externos. ${ }^{20} \mathrm{La}$ inestabilidad fue tan grave que los golpes, revueltas y enfrentamientos se sucedían uno tras otro. La República de Colombia o la del Ecuador, en estado de gestación, en sus primeros pasos no se transformaron ni en un Estado moderno ni en un Estado nacional, cuanto en pequeñas parcelas dominadas por los poderes locales, provinciales o departamentales.

En palabras de Pedro Moncayo, a dos o tres años de fundada la República del Ecuador:

El pequeño Estado del Ecuador con su medio millón de habitantes, parece que consta de otros tres estaditos independientes; cada uno de ellos con todo el aparato, todo el gasto y las rivalidades de las tres naciones separadas. (...)

${ }^{19}$ El historiador liberal Roberto Andrade para referirse a aquellos tiempos recurrió al informe de un agente especial de Estados Unidos para describir el Estado lamentable del país: "En una extensión de 500 millas de territorio ecuatoriano, he encontrado ignorancia, indolencia, pobreza, falta de honradez y envilecimiento en las clases populares, como egoísmo, falsía, ambición sórdida, avaricia y venganza en los directores de las multitudes inconscientes. El país es casi tan miserable como los que lo habitan, y el 90 por ciento de los habitantes no saben leer ni escribir. Se sostiene un gobierno que gasta un millón de pesos anuales, con una renta que no excede de 600 ó 700 mil pesos por año. El pueblo está, en todas partes, dominado por el manto negro de un Clero ignorante, licencioso, indolente y numeroso. La capital del Ecuador participa del movimiento retrógrado general. Los edificios públicos se vienen al suelo. La población es menor de lo que fue 40 años antes, y es tan ignorante e intolerante como entonces. No hay en Quito sino un periódico muy pequeño y muy mal. Ninguna obra de Filosofía, de Ciencia, de Gobierno, de Arte, se ha publicado aquí, en muchos años". Roberto Andrade, Historia del Ecuador, Cuarta Parte. (Quito: Corporación Editora Nacional, 1984), 268.

${ }^{20}$ En Tarqui, a decir del general Sucre: "Enemigos extranjeros (latinoamericanos, ya no españoles) ingratos a vuestros beneficios, y a la libertad que os deben, han hollado las fronteras de la República"; con el sur de Colombia, en 1831. En el Mensaje del presidente Flores al Primer Congreso Constitucional de 1831, se informó que la provincia de Pasto, afectada por los trastornos acaecidos en Bogotá en agosto de 1830, y deseando precaver los males que le acarrearía un porvenir funesto, reclamó la presencia en ella del Jefe de Gobierno de Ecuador. El gobierno de Flores, envío tropas a proteger esta decisión soberana y sus pueblos convocados a elegir, como en efecto eligieron, a 6 diputados al Congreso Ecuatoriano de 1831. En julio del mismo año se produjo el rechazo previsible por parte de Colombia y se desataron de inmediato las acciones bélicas. En un primer momento se perdieron el Chocó, el Cauca y Popayán y, posteriormente, en septiembre de 1832 se vio obligado el ejército de Flores a evacuar Pasto y a firmar un armisticio que se perfeccionó por el tratado de Pasto del 8 de diciembre de 1832. El Ecuador perdió definitivamente esa vasta región y se fijó como límite el río Carchi. "Proclama que el Gral. Sucre dirigió a su ejército antes de la batalla de Tarqui” en Pedro Moncayo y Esparza, El Ecuador de 1825 a 1875. (Quito: Imprenta Nacional, 1907), 22. 
Un Estado así constituido jamás formará un verdadero cuerpo de nación. Siempre será cuestión de Guayaquil, Cuenca o Quito y nunca del Ecuador. (...) Deseamos con ansia que el congreso venidero ambicione la gloria de principiar la época en que, en el Ecuador no haya más que ecuatorianos. ${ }^{21}$

Más allá de las buenas intenciones por integrar todas las partes, lo que quedó en la práctica fue la constitución de un Estado que podía bloquear y debilitar las potencialidades de desarrollo de las provincias/regiones al desmantelar las capacidades de recursos de las provincias, que pasaron a ser dependientes de los recursos financieros que decidía darles el gobierno central, y en esta forma quedaron sometidas a las posibilidades del erario nacional. Las competencias de autonomía o descentralización resultaron difíciles de concretar.

En definitiva, las nacientes Repúblicas de Colombia y de Ecuador, no avanzaron a encontrar condiciones de equilibrio entre lo nacional y lo regional, entre el gobierno unitario o el federal, así como a la demarcación y balance entre renta fiscal nacional y renta fiscal provincial. La flamante república no encontró el hilo de Ariadna que le habría permitido salir del laberinto, no dio con la fórmula capaz de generar las condiciones de viabilidad y de equilibrio entre desarrollo nacional y desarrollo regional/ provincial, así como de demarcación y balance entre renta fiscal nacional y renta fiscal provincial; al no encontrarlo se paralizó su desarrollo y tomó cuerpo un germen de permanente conflicto de intereses entre las provincias o regiones y el Estado central que condujo a la desintegración de la Gran Colombia y posteriormente a la desintegración del Ecuador, crisis de $1859 / 61$. Este conflicto quedó sin resolver y marcó el desenvolvimiento político y económico de las nuevas repúblicas a lo largo del siglo XIX e incluso del siglo XX.

Con otras palabras, continuó con vigencia una forma estatal y de organización del poder de cuño tradicional, que mantenía la estructura del poder central/colonial, lo que sirvió para consolidar un aparato estatal oligárquico, vehículo ideal para la protección de los intereses de los grupos terratenientes y para frenar los impulsos modernizantes. Sobre las

${ }^{21}$ Similar acontecía en Colombia. Túquerres en 1843 no superaba los 36.000 habitantes. La Audiencia de Quito: con los Departamento de Quito, Azuay y Guayaquil, en 1825, no superaba los 230.000. En 1810, el Virreinato de Sta., Fe: 2'150.000 y el de Perú: 1'400.000. El Quiteño Libre, 4 de agosto de 1833, N. 13, 2; en Pedro Moncayo y Esparza, El Ecuador de 1825 a 1875, 109. 
declaraciones jurídicas o constitucionales formales se impuso la realidad desarticulada de las nuevas sociedades, que redujeron la democracia al accionar y a la lucha por el poder entre aristócratas y nuevos grupos medios emergentes, entre el poder central y el poder regional/departamental.

El estado de la América no es el de la Independencia, sino el de una suspensión de armas, (se ha dicho). ¡Cuánto trastorno!... ¡Cuánta sangre! ¡Para conseguir tan poco!... y, cuán lastimoso no sería el perder tantos sacrificios!22

S. Rodríguez alertó sobre las raíces de este mal que ha degenerado en una pandemia que no ha dejado de afectarnos al renacer y reaparecer bajo diferentes formatos, sea suficiente recordar los tiempos en que el populismo ya sea civil o militar ha dominado la escena política. En Sociedades Americanas, cómo eran y cómo podrían ser en los siglos venideros 1828 , primera publicación a su retorno de Europa, llamó la atención sobre esta epidemia:

PERSUÁDANSE LOS REPUBLICANOS, de cuatro cosas importantísimas en su causa”. La primera y la segunda tienen que ver con la constatación, en palabras suyas, de que "Los sabios obedecen a la autoridad: el vulgo... a la persona. Los unos respetan a la Representación, y se conforman con las leyes; los otros rinden vasallaje al representante y se someten a su voluntad. En fin, el sabio - el ciudadano- ve, en la sucesión de magistrados, una prueba de la unidad y de la estabilidad del poder público; el vulgo reconoce otros tantos poderes, cuantos magistrados se suceden, y cree ver expirar y revivir la autoridad con ellos. ${ }^{23}$

De otra parte, en aquellos tiempos el Visitador Juan José de Villalengua emprendió un censo de la población de la Real Audiencia de Quito entre 1778 y 1781. Fue una iniciativa que hacía parte del plan de los Borbones para actualizar la reforma tributaria. Según este censo "los habitantes eran aproximadamente 439.000 . El 26\%, es decir 113.000 súbditos de la Corona eran peninsulares criollos y mestizos blanqueados. De este $26 \%$ de la población total, ¿cuántos eran 'ciudadanos'?, entendiendo por tal a quienes constituían una minoría y solo ellos disponían de los requisitos mínimos de instrucción, bienes, trabajo, propiedad como para 'participar' activamente en la construcción de la nueva República.

${ }^{22}$ Rodríguez, Sociedades Americanas, 19-20.

${ }^{23}$ Ibid., 18. 


\subsection{Emancipación mental}

En la primera fase de conformación de la república tomó cuerpo la problemática de la "emancipación mental" que Simón Rodríguez asumió como condición sine qua non para esculpir el nuevo rostro de la república, problemática esta que apuntaba a completar la emancipación política recién lograda.

Con la denuncia de la civilización-cultura francesa-europea como modelo absoluto, Rodríguez puso sobre el tapete la reformulación del colonialismo, postulando un colonialismo clásico para la época de la dominación española y un neo-colonialismo para los inicios de la vida republicana, dado los caracteres inéditos y diversos que había asumido tal fenómeno en los tiempos de construcción de la república. Otra manifestación clara del nuevo ropaje que habría adoptado el colonialismo, lo denuncia Rodríguez a propósito de los proyectos de repoblar nuestro continente con inmigrantes europeos, pues ellos habrían de traer una nueva "sangre" y habrían de generar, entre nosotros, costumbres de orden y de trabajo. Nuestro autor, por el contrario, revalorizará la política poblacional de los siglos XVII y XVIII, llevada a cabo, por ejemplo, por los jesuitas con sus famosas misiones, en las que, según parece, veía Rodríguez una anticipación de su proyecto de colonias educativas y sobre las que hará girar su plan educacional continental.

Esta nueva 'lectura' de la realidad, también se hizo presente en la exigencia por 'originalidad' y en la revisión del concepto de libertad, que reclama Rodríguez a los americanos acostumbrados a 'imitar servilmente'. Hasta el mismo concepto de filosofía reformula nuestro autor como 'saber de previsión', 'saber de invención', 'saber profético' y de lo 'posible'. Igualmente fue cuestionada y reformulada la categoría de 'civilización', tan profusamente utilizada por los ilustrados como universal ideológico; es decir, como modelo absoluto al cual debían propender los países y que en la práctica se reducía a la imitación y copia de algunas sociedades europeas, particularmente la francesa.

Esta segunda fase del proceso debía realizarse básicamente bajo la mediación de la paz y la égida de la razón, pero ya no de la razón ilustrada sino de aquella que el espiritualismo racionalista -romanticismo- trataba de reformular, por cuanto las luces de la ilustración ya no eran suficientes para iluminar la flamante realidad. 
Con relación a lo primero: la paz, nuestro autor planteó la diferencia de tiempos o épocas que había creado la república en relación a la independencia, lo cual había generado también, necesariamente, una diferencia de medios.

«El árbol de la libertad se ha de regar con sangre» es un concepto verdadero, si por libertad se entiende la «independencia para obrar en favor propio, sin daño ajeno»; pero será un falso concepto, si se cree, que para «entenderse» sobre el modo de obrar, y sentar un principio que regle este modo, sea menester reñir: el resultado sería entonces una guerra perpetua, por consiguiente, la aniquilación ${ }^{24}$

En cuanto a lo segundo: la reformulación del concepto de razón, esta se realizó centrando la crítica en el epicentro de la receta ilustrada: su formalismo y su caída en promesas incumplidas. La razón ilustrada se había manifestado incapaz de implementar las mediaciones necesarias para la plasmación de sus ideales.

Hagan los Directores de las Repúblicas lo que quieran, mientras no emprendan la obra de la "educación social", no verán los resultados que esperan. Nunca saldrán de la fastidiosa repetición de 'principios generales', ni de la interminable disputa sobre derechos y libertades que ; tanto perjudica al crédito de la causa y a la reputación de sus defensores! $?^{25}$

Por supuesto, Rodríguez se percató tanto de las limitaciones del formalismo republicano constitucionalista y del jurídico en que había caído la república, como de la utilización que determinados grupos hacían de dicho formalismo para el mantenimiento de sus privilegios. En tal sentido, Rodríguez anticipa uno de los temas fundamentales de la 'teoría de las ideologías', el de la falsa conciencia, entendida esta como voluntad de engaño, lo que implica, a su vez, la denuncia de una clase y dentro de ella a un determinado grupo, por ejercer la mentira y la utilización de lo sagrado o de los principios seculares para el mantenimiento y justificación de sus privilegios.

Ante los graves problemas que afrontaron los nuevos países, luego de su emancipación: el 'territorial', el 'social' y el 'republicano', tres caras de

${ }^{24}$ Rodríguez, Sociedades Americanas, 20.

${ }^{25}$ Ibid., 34. 
una misma moneda, Rodríguez dio siempre más peso a los dos últimos e hizo así, de su pensamiento, ante todo una filosofía social y republicana, como expresamente supo reconocerlo:

Es un deber de todo ciudadano instruido el contribuir con sus luces a fundar el Estado, como con su persona y bienes a sostenerlo. El autor de esta obra ha procurado reunir pensamientos en favor de la causa social. ${ }^{26} \ldots$ El fundamento del sistema republicano está en la opinión del pueblo, y esta no se forma sino instruyéndolo ${ }^{27}$

Por otra parte, a juicio de Rodríguez, la situación post-independendista tampoco había logrado resolver otro género de limitaciones heredadas de la Colonia pues, prácticamente, a década y media de la declaración de independencia de nuestros pueblos:

Somos "independientes", pero no libres, (...) dueños del "suelo" pero no de "nosotros mismos". Las preocupaciones políticas que nos dominan, no caducarán como muchos lo esperan; al contrario: persisten al lado de las Ideas Liberales, las harán bastardear. Otras fuerzas que las que empleamos para "emancipar debemos emplear para "liberarnos" (...) las de la Razón. Contra los soldados del Rey peleamos con las manos, contra las preocupaciones hemos de pelear con la cabeza, seguros de que, los errores más febles se burlan de las balas, y los más robustos ¡tiemblan! (...) al ver asomar la verdad, esta se arma con plumas, en lugar de fusiles ${ }^{28}$

Además de la denuncia del formalismo republicano e ilustrado y su implementación ideológica, Rodríguez revisó otros componentes más. Desmontó, por ejemplo, la visión ilustrada de lo social, incapaz de comprender que la sociedad no era una mera agregación de individualidades o átomos sino más bien, una asociación o relación dinámica de las partes.

Es tan obvia, dirá, la diferencia entre conexión y relación, que no sería menester indicarla, si todos fueron escrupulosos en el valor de los términos. Están las cosas 〈conectas〉, cuando están juntas o adherentes, y tienen 〈relaciones〉, cuando obran unas con otras, o unas en otras. No es menester decir que los hombres viven juntos, porque en ninguna parte se les ve

\footnotetext{
${ }^{26}$ Ibid., 6.

${ }^{27}$ Rodríguez, "nuevo medio", en Obras Completas, tomo I, 241.

${ }^{28}$ Rodríguez, Obras Completas, tomo I, 240, tomo II, 427-428.
} 
aislados. En cuanto a sus relaciones, unas le son forzosas como las de la familia, y otras son ocasionales como las que contrae por negocios. Todos saben esto, sin estudiarlo; un conjunto por agregación. ${ }^{29}$

\subsection{El sistema o régimen testamentario}

De todas estas y otras problemáticas, hay una en que su análisis además de reiterativo o permanente, es original frente al sistema colonial. La nueva situación había heredado mucho del pasado y, en más de un aspecto no había logrado romper el cordón umbilical que le ataba al caduco sistema colonial, básicamente por razones testamentarias. Con otros términos, la sociedad colonial se reproducía y se mantenía incólume en medio de la vida republicana, a través de un sistema o régimen testamentario, que cubría un amplio abanico de posibilidades: transmisión de la tradición, de la herencia, de la tierra, de las leyes, costumbres, matrimonios, profesiones, etc.

Se trataba de un sistema establecido con carácter dogmático por nuestros mayores o antepasados, a partir de una comprensión de la sociedad como una realidad inamovible. No se pensaba que el sistema de relaciones vigente podía ser alterado o que, al menos, necesitase de un cambio más allá de lo político. A su criterio, todo se había convertido en un acto testamentario y la misma vida de los hombres aparecía organizada bajo la forma de un testamento o herencia desde su nacimiento hasta su muerte:

Haber criado a un niño hasta cierta edad... es un derecho para impedirle que tome el Estado o profesión que le conviene o agrada como para forzarlo a tomar (sin decir por qué) el que no le conviene o repugna. Moribundo que tiene algo, por poco que sea, es legislador, y los vivos le han de obedecer: si es grande el caudal, dispone que su heredero viva ocioso, y manda que se le aguanten todas sus impertinencias, (...) y si poco antes de morir, la enfermedad no le ha hecho perder el juicio, las leyes le mandan que hable como un loco, diciendo que lleva lo que no puede llevarse. (De este modo) la potestad paterna influyendo en la educación y en la elección de estado o profesión... y las leyes concediendo y protegiendo la facultad de Testar, son dos inconvenientes para emprender la obra de la República. ${ }^{30}$

\footnotetext{
${ }^{29}$ Rodríguez, Sociedades Americanas, 280-281.

${ }^{30}$ Ibid., 278.
} 
Junto a los momentos fundamentales del ciclo vital humano, signados por lo testamentario o hereditario, Rodríguez descubrió otros no menos importantes en el desarrollo humano, pero también marcados por la impronta testamentaria: la transmisión de la propiedad privada, de las herencias, de los signos especialmente el lenguaje y particularmente la escritura que se organizaban también, a su criterio, bajo pautas heredadas y se hacía por ende necesario innovar también estos ámbitos. "Las sociedades, -dirá Rodríguez-, tienden a un modo de existir, muy diferente del que han tenido, $\mathrm{y}$ del que se pretende que tengan ${ }^{31}$.

En la crítica a la educación testamentaria abundó y como prueba sea suficiente un ejemplo:

Los Maestros de Escuela han sido, son (...) y serán mientras dure la monarquía (...) (que será hasta el fin del mundo) unos pobres dependientes o ayos mal pagados, especies de bocinas que suenen como las soplan: su oficio es... 'Engañar muchachos por orden de sus padres'. Los Rectores de los Colegios hacen un papel serio en la comedia. Aparentan rigidez en el cumplimiento de las reglas de unos Estatutos, calculados para adular a los padres, haciendo lo que exigen que se haga con sus hijos. Encierro, cepos, calabozos, estudio continuo, sabatinas, argumentos de memoria, confesiones forzadas, ejercicios de San Ignacio, exámenes, premios, grados, borlas... mientras se les preparan 'espoletas' en lugar de 'charreteras', bufetes de abogado, enlaces de familia, y si hay con qué, viajes a Europa para olvidar su lengua y volver con crespos a la francesa, relojitos muy chiquitos con cadenitas de filigrana, andando muy ligeros, saludando entre dientes, haciendo que no conocen a los conocidos y hablando perfectamente dos o tres lenguas extranjeras... ${ }^{32}$

Una visión tan crítica de la educación vigente, incluida las formas escritas de su transmisión, planteaba la necesidad de reconstruir todo el escenario, ya que la educación testamentaria presentaba un conjunto de notas que formaban una unidad, fuertemente trabada y ensamblada, difícil de desarticular. Así, por ejemplo, la enseñanza testamentaria generaba una pérdida de la identidad cultural, desadaptación de la enseñanza a las necesidades del estudiante y la comunidad, predominio de metodologías de enseñanza pasiva y autoritaria, orientadas a su vez a la memorización y a la consecución de determinado

${ }^{31}$ Ibid., 69.

${ }^{32}$ Ibid., 285. 
status social. En fin, un contexto abatido, propio de una región arrasada por la crisis demográfica, los extraordinarios gastos que demandó la guerra, las divisiones internas, la deuda con Inglaterra, etc.

\section{La propuesta de Simón Rodríguez: educación Republicana}

Descrito el escenario general o marco político es hora de introducirnos en el ámbito educativo. ¿Qué debía transformar a la educación colonial o testamentaria en verdadera educación republicana? ¿Qué estrategias y políticas había que cultivar en el ejercicio docente? Paso a detenerme en algunas de las características de tal tipo de educación. El anuncio de un porvenir diferente en la educación por construir se diseñó a partir de las siguientes orientaciones o pautas políticas:

\subsection{Educación pública}

La educación debía concebirse como educación pública antes que privada y confesional, con los ojos puestos más en los niños pobres, y especialmente en los indígenas, que en otros. Por lo primero, Rodríguez se adhiere al postulado ilustrado del Estado-Educador, sin posibilidad de descargo de esta misión que anteriormente estaba en manos del clero y órdenes religiosas; proceso de secularización de la educación. Por lo segundo, confiere al proceso de democratización de la educación, el contenido social que le hacía falta, si se quería que los esfuerzos del Estado no terminaran favoreciendo a los grupos privilegiados de siempre, lo que generaría nuevas diferencias, básicamente cualitativas, a partir de la misma educación. Optar por una política educativa a favor preferentemente de niños pobres e indígenas, supuso preferir la educación primaria a la secundaria, opción que el sistema educativo vigente era reacio a aceptar, ya que la educación privada primaria era más fácil de llenar por los padres de familia pudientes, necesitados ellos más de colegios que de escuelas. En este aspecto, la opción de Rodríguez es una prueba más de su categórica orientación social.

En diferentes ocasiones intentó Rodríguez institucionalizar este tipo de centros educativos. En un primer momento, en Bogotá (primeros meses de 1824), a poco tiempo de su retorno de Europa (primeros meses de 1823), cuando levantó una Casa de Industria Pública, institución en la cual se 
prepararían los estudiantes no tanto para la vida intelectual y las profesiones tradicionales, cuanto para el ejercicio de oficios técnicos y el aprendizaje de conocimientos prácticos y útiles, orientación esta contraria al espíritu de la aristocracia española y la criolla que minusvaloraba el trabajo manual y las profesiones técnicas. Esta experiencia duró poco.

Años después, en Bolivia, (enero de 1826), "se dedicó Rodríguez a organizar la Casa de Chuquisaca. En menos de cuatro meses (...) reunió más de 200 niños, cerca de 50 pobres y 20 jóvenes de diferentes partes que aprendían para propagar la instrucción en otras ciudades" ${ }^{33}$. Este segundo intento, al igual que el de Colombia, tampoco logró mayor éxito y terminó en medio de enfrentamientos y tensiones. Si se hubiera hecho caso a su propuesta, "los campos estarían cultivados, y los labradores tendrían casas bien construidas, mobladas y limpias; estarían decentemente vestidos, se divertirían con moderación y entenderían de sociales; en unas palabras serían ciudadanos" ${ }^{34} \mathrm{El}$ proyecto de Chuquisaca, a criterio de algunos entendidos, era más desarrollado y completo que el de Bogotá, e igual se podría afirmar del proyecto de Latacunga que supo reunir los anteriores avances. Además, Consejos de Amigo también sirvió para reformular su Extracto sucinto de la obra Educación Republicana, escrito a poco de abandonar Latacunga con destino a Bogotá, en una obligada parada en Túquerres, 1849, donde permaneció dos años. Consejos y el Extracto podrían hoy ser vistos como una sola propuesta, y ambos a su vez están vinculados con el plan educativo de Rodríguez para Bolivia, publicado en Arequipa en 1830.

\subsection{Educación republicana o de formación de ciudadanos}

Sin que esto signifique establecer un orden de preeminencia o de jerarquía en las notas determinantes del modelo, la educación social debía ser también educación republicana o de formación de ciudadanos, en oposición a la monárquica, cuyas características fundamentales, a pesar de haberse terminado formalmente el orden colonial, subsistían aún en la enseñanza y en la vida pública, orientada a la formación de siervos sometidos aún al peso de la autoridad sea local, virreinal o real. Reaccionar servilmente ya

${ }^{33}$ Jesús Andrés Lasheras, "Ensayo: Simón Rodríguez en sus cartas”, Simón Rodríguez Cartas, (Caracas: Ediciones Rectorado-Universidad Nacional Experimental Simón Rodríguez, 2001), 60.

${ }^{34}$ Rodríguez, Sociedades Americanas, 258. 
no era la conducta apropiada, se hacía necesario cuestionar y reformular categorías como la de sometimiento a las personas y obediencia a la autoridad, lo primero muy propio del régimen monárquico y de los gobiernos populistas.

\subsection{Educación social en el campo}

La educación social debía orientarse más al "campo" que a la "ciudad", prefiriendo las escuelas de agricultura y maestranza sobre las humanísticas, dado el desequilibrio que, en uno y otro aspecto, ofrecía el sistema educativo vigente, con las consiguientes limitaciones y deficiencias que esto generaba. Precisamente, en Consejos de Amigo... Rodríguez desarrolla la tesis de que la tarea educativa debía marchar del campo hacia la ciudad, convirtiendo al campo en el "lugar" educativo por excelencia y no al revés. "Si los americanos quieren que la revolución política que el peso de las cosas ha hecho y que las circunstancias han protegido, les traigan verdaderos bienes, hagan una revolución económica y empiécenla por los campos: de ellos pasará a los talleres y diariamente notarán mejoras que nunca conseguirán empezando por las ciudades". ${ }^{35}$

De por medio estaba la crisis demográfica ocasionada por décadas de guerra. Por ejemplo: Quito en 1780 tenía 25.000 habitantes, en 1840: 20.000; Ambato pasó de 4.000 a 2.200; Latacunga de 3.400 a 2.200; Riobamba de 7.600 a 3.600$)^{36}$. Además, en los centros urbanos se vinculaban: la élite de gobierno, el clero y la plebe urbana: artesanos, albañiles, sastres y zapateros...; en el área rural se concentraba la mayoría de la población y principalmente los pueblos indígenas. Lo urbano, manifestación de lo social y cultural, además facilitaba la construcción de sentidos y formas de dominación.

Conviene rescatar que la tesis del campo como espacio de la educación por excelencia, o la "marcha" de la tarea educativa del campo hacia la ciudad y no viceversa, la apuntaló Rodríguez con una serie de elementos teóricos y de su observación o experiencia práctica que recomendaban este giro copernicano. Las ciudades, pervertidas por el «régimen testamentario», requerían ser purificadas; el país necesitaba

\footnotetext{
${ }^{35}$ Rodríguez, “Consejos de amigo” en Obras completas, tomo I. 241 y 231-240.

${ }^{36}$ Enrique Ayala Mora, ed. "Época Republicana”. Nueva Historia del Ecuador, Vol. 7, (Quito: Ed. Corporación Editora nacional-Grijalbo, 1990), 48.
} 
dar más importancia al comercio interior que al exterior; remplazar los artículos industriales que venían de Europa y estaban sustituyendo y acabando con los tradicionales productos de nuestras artesanías; detener la larga y costosa importación de Europa de retortas, termómetros, barómetros, primas, hornillas, alambiques, campanas de vidrio,... que podrían fabricarse en nuestras maestranzas; desarrollar la industria, pues de ella provenían las riquezas durables; terminar con el abandono de las artes mecánicas; ocupar la mano de obra; desarrollar mecanismos de financiamiento para los colegios; superar la división del trabajo propia del régimen manufacturero e industrial que reducía al hombre a la condición de instrumento... requerimientos todos ellos y otros más que el proyecto de educación social enfrentó a través de las nuevas formas de educación y trabajo que él intentaba implementar en centros escolares ubicados en el campo, en el espacio rural.

Basándose en la experiencia que develaron las marchas con el ejército libertador a todo lo largo de cada uno de los países bolivarianos pudo Rodríguez de igual modo visibilizar que tanto en el bando realista como en el de los patriotas, los jefes de ambos ejércitos eran hombres de ciudad, propensos a la civilización europea más que a los paradigmas de los pueblos indígenas y que traían aparejado una concepción de la sociedad que era urgente revertir. "O inventamos o erramos".

De esta forma también quedó marcado un espacio como reverso de otro y la ciudad concebida como centro de dominación y el campo en una especie de topos alternativos en el que era posible dibujar como en contraste el futuro añorado. La imagen de la ciudad como sitio de perversión y del campo como lugar de un desarrollo natural tenía ya antecedentes en la obra de J.J. Rousseau que llamaba a defenderse de la contaminación y corrupción de la ciudad visualizada como el lugar donde más se alejaba el hombre de su naturaleza, por lo cual se recomendaba a los padres de familia trasladar la educación de sus hijos de la ciudad hacia colonias ubicadas en el campo.

La naturaleza se juzgó que era un instrumento idóneo para formar el carácter del niño, quien en contacto con la naturaleza debía evolucionar, física y psíquicamente, de forma favorable y virtuosa, por lo que se consideraba positivo no sólo la educación a través de la naturaleza sino también la educación en la naturaleza. El valor asignado a la observación de la naturaleza y al cultivo de la sensibilidad en cuanto instrumento de 
acercamiento y conocimiento de ella se patentiza: p. ej. en el párrafo de apertura de la Instrucción Previa que elaborara Espejo al lanzar a circulación Primicias de la Cultura de Quito:

La primera vista que demos sobre la naturaleza del hombre, hallaremos, que él es dotado de talento de observación; y que las necesidades que le cercan obligan a todos momentos a ponerlo en ejercicio. Si el hombre se ve en la inevitable necesidad de hacer uso de este talento desde los primeros días de la infancia; es visto que de este principio depende, el que él vaya sucesivamente llenándose de ideas; comparando los objetos; distinguiendo los seres. De aquí la feliz progresión de sus conocimientos destinados a la conservación de la vida, al cultivo de la sociedad y a la observancia de la piedad. ${ }^{37}$

La doctrina sobre la naturaleza, como ya lo hemos señalado, jugó un papel capital y el "modelo naturalista" alcanzó vigencia a todo lo largo del siglo XIX y gran parte del XX. En el ámbito pedagógico, Pestalozzi por ejemplo, con sus paseos y salidas al campo y su continuador Froebel son ejemplos claros. En ellos así como en la pedagogía idealista o propia del romanticismo, se intentaba adecuar y ensartar dos ideas básicas: en primer lugar, valorar la naturaleza humana como obra divina que es, y por tanto sin tara; en segundo lugar, desarrollar (o educar) convenientemente a esa naturaleza humana, sin mancillar ninguna de sus virtudes o valores, $o$ desvincularla del trato con la naturaleza. ${ }^{38}$

No faltaron sin embargo visiones del sector rural de sentido opuesto, como la dibujada por Domingo Faustino Sarmiento, en que el campo es visto al revés e identificado como centro de retraso en el orden económico, político y cultural y como el reto primordial a superar por los pueblos latinoamericanos. La metáfora se trasladó del análisis de Argentina al análisis de Sudamérica concebida como continente en situación de «barbarie» en claro contraste con Europa, Norteamérica y las ciudades visualizadas como cunas de la «civilización». ${ }^{39}$

${ }^{37}$ Eugenio Espejo, Primicias de la Cultura de Quito, (Quito: Publicación del Archivo Municipal, 1947), 56.

${ }^{38}$ Antoni J. Colom y Joan-Carles Lélich, Después de la Modernidad, Nuevas filosofias de la educación, (Barcelona: Paidós, 1994), 161-162.

${ }^{39}$ Domingo Faustino Sarmiento. Facundo o Civilización y Barbarie, (Buenos Aires: Biblioteca del Congreso de la Nación, 2018), 368. 


\subsection{Unidades de experimentación y producción}

La educación social debía transformar a los centros educativos en unidades de experimentación y producción. Lo primero partía del supuesto de que la ciudad era el lugar donde más se había alejado el hombre de la naturaleza, por lo que era necesario arrancar a los niños de dicha contaminación, a fin de protegerlos en colonias infantiles en las que se experimentasen nuevas formas de contacto con el medio natural, a través de las cuales el niño, particularmente pobre o indígena, pudiese incorporar a su vida de estudios la vida familiar, social y de producción. Lo segundo partió del supuesto de que la sociedad agro-artesanal no requería necesariamente ser barrida por la sociedad industrial y los vientos del "progreso".

La división del trabajo, en la confección de las obras embrutece a los obreros y que, si por tener tijeras superfinas y baratas hemos de reducir al Estado de máquinas a los que las hacen, más valdría cortarnos las uñas con los dientes (...) Por el buen nombre de la Fábrica, el obrero se reduce a la condición de instrumento: ¡toda su vida cantando, toda su vida tejiendo! al fin se convierten los hombres en lanzaderas y en serruchos... ${ }^{40}$

Con todo lo cual, la tarea pedagógica apuntaba a rescatar al hombre a partir de una nueva forma humana de trabajo, síntesis no fácil de alcanzar. El trabajo artesanal en aquella época daba ocupación a un considerable número de pobladores en las ciudades: la construcción, restauración y reparación de casas, la confección de la ropa y calzado, el mantenimiento de servicios básicos de agua y luz, la confección de artesanías y productos para la casa, ocupaban a los artesanos y trabajadores de empresas pequeñas y familiares.

\subsection{Colonias para adultos}

La educación social propuso, además de colonias infantiles, colonias para adultos, sugerencia que rompía los estrechos marcos de la organización educativa tradicional, concentrada en el sistema regular o formal e incapaz de abrirse al mundo de los mayores.

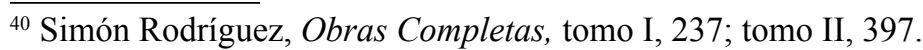


En vida de Bolívar, dirá su maestro, pude ser lo que hubiera querido, sin salir de la esfera de mis aptitudes. Lo único que le pedí fue que se me entregaran, de los Cholos más pobres, los más despreciados, para irme con ellos a los desiertos del Alto- Perú, con el loco intento de probar, que los hombres pueden vivir como Dios les manda que vivan... ${ }^{41}$

Ahora bien, la educación de adultos no tenía como propósito educar a ese "populacho" para que ingrese al orden vigente, orden que dicho grupo humano se negaba a aceptar, sino más bien prepararle para un régimen que habría de establecerse bajo nuevos parámetros y un nuevo concepto de propiedad, llevada a la práctica de manera comunitaria y con formas de vida que luego se extenderían a las ciudades.

La Isla de Tomás Moro adquiere en Rodríguez, dice un autor, una de las formulaciones más interesantes que pueda verse dentro del utopismo americano. 'Aislar' el mundo americano del europeo, asegurándonos con ello para nosotros el único lugar que quedaba para la Utopía; aislar dentro de la América, con sus comunidades experimentales, las establecidas en los desiertos, a los que serán los hombres del mañana. El desierto y el campo se transformarían, de esta manera y por necesidad en el 'topos' del 'topos', el 'lugar' por excelencia dentro del único 'lugar'. Mas, en última instancia, el 'aislamiento', como ya lo era en Moro y lo fue en otros utopistas, era un momento dialéctico, que exigía su propia negación. Aislar a América para que desde ella surgiera una auténtica civilización; aislar dentro de ella a los pobres, es decir, los moldeables en cuantos huérfanos de toda 'herencia' y ajenos, por eso mismo, a los vicios del sistema testamentario, para que desde sus colonias surgiera la ciudad futura. 'Utopía' como 'ciudad cerrada' y 'Cosmópolis' como 'ciudad abierta', son los dos extremos de la marcha dialéctica propuesta por ese gran maestro de América.

En definitiva, Reforma de la Educación, pero bajo replanteos que, aún hoy en día, continúan siendo un reto a alcanzar y estamos llamados, bajo nuevas circunstancias, a emprenderla. En palabras del mismo Rodríguez:

¡El interés general está (y continúa) clamando! por una REFORMA de la educación y la AMÉRICA! ¿¡Quién lo creería!?... está llamada por la CIRCUNSTANCIAS, a emprender, pero los parámetros sobre los que debía caminar la reforma debían ser igualmente diferentes: ¿Dónde iremos

\footnotetext{
${ }^{41}$ Simón Rodríguez. Obras Completas, tomo I, 255.
} 
a buscar modelos? -La América Española es original == ORIGINALES han de ser sus instituciones i su gobierno $==\mathrm{i}$ ORIGINALES los medios de fundar uno i otro. O inventamos o erramos (sic) $)^{42}$

En síntesis, el Extracto sucinto formulado en Túquerres y editado en Bogotá 1849, y los Consejos de amigo... 1851 y editados un siglo después en Quito, en 1954, realizaron la síntesis o conjunción tanto de los planteamientos sobre la urgente necesidad de conformar la República y a su vez, vincular a la educación con las demandas políticas y sociales de los sectores emergentes -educación popular-, y además a ella con los planteamientos pedagógicos que hacían de la Educación Republicana con específicos fines educativos, metodología de enseñanza, organización, actores, participación de la comunidad, tipo de profesorado, producción, etc. en la fórmula requerida en dicha aciaga hora, con clara orientación hacia los grupos en extrema pobreza -educación social-.

\section{Aportes a la metodología educativa}

A los planteos educativos expuestos, Rodríguez supo unir los aspectos metodológicos y didácticos, capaces de dar viabilidad a su propuesta. Consideró necesario alterar por sus bases a la misma práctica o ejercicio de la enseñanza, y en este campo tampoco dejan de ser sorprendentes sus aportes que, a más de un siglo, no han perdido actualidad.

\subsection{Crítica al Sistema Lancasteriano}

Por la insuficiencia del Sistema Lancasteriano, adoptado directamente por el mismo Libertador, seguramente como fórmula de emergencia para dar instrucción elemental a grandes masas de la población, pero que, según Rodríguez, no era el método ideal para educar sino, a lo más, para instruir, tomando en cuenta que, "instruir no es educar, ni la instrucción puede ser un equivalente de la Educación, aunque instruyendo se eduque". ${ }^{43}$

En el sistema de Lancaster los alumnos se dividían en grupos entre diez y veinte y los más aventajados instruían a sus compañeros en lectura, escritura, cálculo y catecismo, del mismo modo en que ellos habían sido

\footnotetext{
${ }^{42}$ Ibid., 343-234.

${ }^{43}$ Rodríguez. Obras Completas, tomo II, 104.
} 
enseñados por su maestro horas antes. Prevalecían en el ejercicio docente los ejercicios de repetición de los contenidos, en voz alta y acompasadamente, a fin de afianzarlos en la memoria. Los alumnos aventajados se denominaban monitores y, además de ellos, había en el aula otro funcionario: el inspector, encargado de vigilar a los monitores, de entregar y recoger los útiles de enseñanza e indicar quiénes debían ser premiados o corregidos.

La crítica y aun la sátira que despertó en Rodríguez este sistema, ha conducido a afirmar que "en el maestro caraqueño hubo un anti-Lancaster nato”, que no consideraba admisible la 'enseñanza mutua' por múltiples motivos: no era saludable que operase como maestro quien no estuviese instruido y preparado para hacerlo; no dejaba de ser un disparate intentar aprender de memoria determinados contenidos, y peor aún, repetir o dar gritos, que no hacían más que formar charlatanes.

Si para obtener empleos, decía al Ayuntamiento en Reflexiones sobre el estado actual de la Escuela 1794, se necesita instrucción, talento, aplicación y conducta en los sujetos; para servir a las escuelas deben ser doblemente instruidos los maestros, aplicados e irreprensibles y haber acreditado estas cualidades. Considérese la grave obligación de un maestro y responsabilidad ${ }^{44}$. En "Consejos de amigo", repetía: Enseñanza mutua es un disparate: Lancaster la inventó, para hacer aprender la Biblia de memoria (...) Dar gritos y hacer ringorrangos no es aprender a leer ni escribir. Mandan recitar, de memoria, lo que no se entiende, es hacer papagayos, para que... por la vida isean charlatanes (...) Las escuelas se dividen en dos especies: unas para niños decentes (es decir, que pagan bien). Estas son Enciclopedias, para hacer sabios a 10 años. Otras, para la moralla-almacenes de muchachos, enseñándose unos a otros a gritar, y los Maestros... (digo mal) los 'preceptores', mandando (a uso de los Pilotos) la maniobra: son Escuelas de vapor, de la fuerza de 100 caballos, o ferrocarriles, que transportan en un soplo millares de muchachos de la sima de la ignorancia al pináculo del saber ${ }^{45}$

Nos hemos detenido en el examen del sistema lancasteriano, porque el caso ilustra adecuadamente los afanes de orden cualitativo que encerraba el proyecto de Rodríguez, y, si bien las políticas de ampliación de la enseñanza constituían imperiosa necesidad, no menos urgentes eran las conquistas cualitativas, aspecto en que nuestro autor mostró especial interés.

\footnotetext{
${ }^{44}$ Ibid., 76.

${ }^{45}$ Ibid., 25; 76; 199-203; 247.
} 


\subsection{Observación, reflexión y meditación}

La observación, reflexión y meditación provienen del énfasis puesto por Rodríguez en el análisis de la actividad o proceso del aprendizaje, más que en la misma fase de información o desarrollo de los contenidos que implica la enseñanza. A su criterio, el proceso de aprendizaje podía descomponerse, para efectos del análisis, en los siguientes momentos: 'observación', que era "un ponerse delante de un objeto para guardarlo, es decir, para apropiárselo"; 'reflexión', que era un "hacer reflejar la imagen entre el objeto que la da y el sentido que la recibe", y 'meditación', que era un "ponerse en medio de las imágenes para compararlas, viendo a un lado y otro". En fórmula condensada: "abrir los ojos para observar, fijarlos para reflexionar y cerrarlos para meditar". ${ }^{46}$

De interés es señalar que, por lo primero: la observación, el proceso de aprendizaje quedaba anclado en la 'naturaleza', con múltiples ventajas para el educando:

Ya que conocer a la naturaleza en cuanto nos es permitido... es un deber porque estamos rodeados de cosas, y sorprendidos por accidentes, que llamamos circunstancias, y frente a fenómenos que, en muchos casos, nos conviene saber explicar. Dependemos de las circunstancias, luego, es menester acostumbrarnos a obedecerles. Si en el Colegio se enseñaran la Ciencias Exactas y de Observación, los jóvenes aprenderían a apreciar lo que pisan, y se abrirían muchas carreras. ${ }^{47}$

Por los otros aspectos: reflexión y meditación, el aprendizaje quedaba anclado en el 'sujeto', manteniéndose así una relación dinámica y dialéctica entre uno y otro polo, relación que no lograba superar un tratamiento mecánico o subjetivista del aprendizaje. De este modo, Rodríguez no redujo el aprendizaje a un mero saber de las propiedades de las cosas, para poder adecuarnos a ellas (empirismo-positivismo), pues el aprendizaje supuso para él, algo más que una posición pasiva, al implicar también un momento activo de parte del sujeto, momento este último que era como una 'pretensión', una 'espera' y un señalamiento del 'lugar' de la pretensión y la espera, sin que todo esto significara caer en delirios (idealismo - utopismo).

\footnotetext{
${ }^{46}$ Rodríguez. Obras completas, tomo I, 253.

${ }^{47}$ Ibid., 44.
} 
Una descripción más clara que la del año 49, a que se ha hecho referencia, consta en "Consejos de Amigo", que dada la importancia del tema nos permitimos transcribir:

Observar, es ponerse delante de un Objeto, a examinarlo para conocerlo, con intención de guardarlo, o de guardar la imagen, para sí; reflexionar es hacer reflejar la imagen del objeto, contra el objeto mismo, por el sentido que ha recibido la impresión: es tratar de grabarse bien la imagen, para que no se confunda con otras, o se borre: meditar es ponerse en medio del objeto, y de la imagen que ha dejado, en el sentido, para ver si se le asemeja: es también, comparar los resultados de dos o más acciones para prever sus consecuencias. El gobierno... o el que manda, sea lo que fuere, debe abrir los ojos para observar, fijarlos para reflexionar y cerrarlos para meditar ${ }^{48}$

Esta visión del aprendizaje como un desarrollo que incluye el despliegue de diferentes fases: observación-reflexión-meditación, condujo a concebir otros componentes del proceso educativo, a partir de dicha base, con lo cual se puso de manifiesto la riqueza de virtualidades que ella encerraba. Así, por ejemplo, 'estudiar' era "aplicarse y contraerse mentalmente"; 'maestro' quien "enseña a aprender y ayuda a comprender" a partir de un 'saber para sí' y un 'saber transmitir'. Igualmente, esta concepción llevó a juzgar el aprendizaje en su insoslayable vinculación con la enseñanza, proceso de interaprendizaje en la terminología actual, y, además, exigió que no se descuidara todo lo pertinente al proceso de expresión de los contenidos:

...a pronunciar, a articular, a acentuar, a fijar la Significación de las Voces, y las propiedades de los términos, a dar a las frases, el énfasis que pida el pensamiento, a pensar con propiedad, las Ideas, notando la Cantidad y el Tono que deben distinguirlas: porque, tan necesaria es la Cantidad en la Sílaba, para que sea palabra, como el tono en la palabra para que la Locución exprese un Sentimiento ${ }^{49}$

Una consecuencia de orden social y político de la presente concepción del aprendizaje habría sido el que, en la escuela primaria, se hubiese enseñado a raciocinar y "habría menos embrollones en la sociedad. Empachados de silogismos, salen los jóvenes de los colegios, a vomitar

\footnotetext{
$\overline{48}$ Rodríguez. Obras completas, tomo II, 30-31.

${ }^{49}$ Ibid., 26-27.
} 
paralogismos, por las tertulias. De ahí vienen los sofismas, que pasan por razones, en el trato común y llegan hasta a ser razones de Estado, en los gabinetes ministeriales". .50

Para Rodríguez no cabía una 'sociedad moderna' sin el libre ejercicio de la Razón. Obedecer ciegamente fue el motor de la sociedad monárquica y por eso existían tantos esclavos y era amo el primero que se proponía serlo; mientras que en las sociedades republicanas se debía obedecer a la Razón y "no a la autoridad, como los limitados, ni a la costumbre, como los estúpidos". ${ }^{51}$

\subsection{Aprendizaje memorístico y aprendizaje comprensivo}

Proveniente de la diferenciación que estableció entre lo que podría denominarse 'aprendizaje memorístico' y 'aprendizaje comprensivo', que le sirvió para delimitar con precisión la línea de demarcación entre la escuela lancasteriana y su propia propuesta, y contrastar los aspectos cuantitativos de los cualitativos. De acuerdo a la primera propuesta, el niño memorizaría los contenidos, pero sin comprenderlos, con los nocivos efectos que el conocimiento superficial genera y que Rodríguez supo ridiculizar:

Leer, escribir y contar, es la carretilla de las primeras escuelas. Leen, porque dicen atropelladamente lo que está en un librito, que saben de memoria. Escriben, porque llenan páginas enteras de rasgos y palotes, de prisa para acabar pronto. Cuentan, por que cantan, a gritos, la tabla, dicen... dojvejdoj=cuatr; trejvejsis=disioch...Después de haber hecho cantar, $;$ a sus discípulos...por meses enteros: pe-ápa, pe-épe, pe-ípi, pe-ópo, pe-úpu, y para que se perfeccionen...pane-pan, pene-pen, pini-pin... ${ }^{52}$

La lectura, en tal sentido, era el lugar privilegiado para mostrar las diferencias entre una y otra posición, y además permitía establecer que solo un aprendizaje comprensivo, apoyado en el ejercicio de la razón, era capaz de penetrar y descifrar los secretos del texto. Leer es resucitar ideas sepultadas en el papel: cada palabra es un epitafio: llamarlas a la vida es una especie de milagro y para hacerlo es menester conocer los espíritus de las difuntas, o tener espíritus equivalentes que subrogarles. ${ }^{53}$

\footnotetext{
${ }^{50}$ Rodríguez, Obras completas, tomo II, 26; tomo I, 243.

${ }^{51}$ Rodríguez, Obras completas, tomo II, 27.

${ }^{52}$ Ibid., 28.

${ }^{53}$ Rodríguez, Obras completas, tomo I, 243; tomo II, 29.
} 


\subsection{Las experiencias y el conocimiento significativo}

El conocimiento significativo provino de la valoración que otorgó Rodríguez al 'mundo de experiencias' del educando, a su criterio, insoslayable para el aprendizaje, porque las experiencias del niño, en la dimensión personal y social, no solo servirían para la motivación y activación del deseo de aprender, también para enfrentar las barreras que dificultaban el aprendizaje y determinar los contenidos de la enseñanza; de allí la necesidad de prestar atención al bagaje de experiencias para desatar aprendizajes.

Caso contrario, de no auscultarse el bagaje de experiencias: necesidades y capacidades, aspiraciones y dificultades del niño, motivaciones y rechazos, la enseñanza terminaría elaborando abstracciones que el estudiante será incapaz de seguir, sea porque nunca las había observado directamente relacionadas con su experiencia, sea porque no correspondían a las situaciones y condiciones concretas de su entorno -Conocimiento significativo-.

Tomó cuerpo esta propuesta a través de ejemplos en los que él desarrolla determinados contenidos, a partir de experiencias. A propósito de la enseñanza de gramática, decía: "Los nuevos maestros de la escuela primaria no necesitarán molestarse en recoger barbarismos y solecismos, los muchachos se los traerán: háganlos hablar y tendrán qué corregir: esa será su Gramática". ${ }^{54}$ Igualmente ilustrativa es la comparación de la primera escuela con la palanca de primer género, que "excitará en muchos la curiosidad de saber lo que es potencia, resistencia, y punto de apoyo o Hipomocli..." ${ }^{55}$ Más claro aún es el siguiente texto:

Establezca el gobierno una escuela en que se enseñe la lógica, el idioma y el cálculo, por principios; y como los principios están en las cosas, con cosas se enseñará a pensar. Se nombrarán cosas y movimientos que se vean, oigan, huelan, gusten y toquen, haciéndolos mirar, escuchar, olfatear, saborear y palpar. Se hará conocer con voz y boca, cómo se forma la una y cómo se emplean las partes de la otra para pronunciar. Se harán consistir las letras en el movimiento de la mano, no en apretones y cabellos. Se hará entender que se habla para el oído y se escribe para el ojo... ${ }^{56}$

\footnotetext{
${ }^{54}$ Rodríguez, Obras completas tomo II, 43.

${ }^{55}$ Ibid., 13-14.

${ }^{56}$ Rodríguez, Obras completas, tomo I, 401.
} 
No hay que olvidar que los aportes metodológicos de Rodríguez no solo se postularon a nivel de la teoría, sino que se concretaron, y esto es lo sorprendente, en la estructura del mismo texto, en una praxis literaria de carácter eminentemente pedagógica, como lo testimonia la forma peculiar de organizar y desarrollar sus escritos. En efecto, llama la atención, como lo advirtiera Aurelio Espinosa Pólit, primer editor de Consejos de Amigos dados al Colegio de Latacunga:

La disposición peculiar del Escrito, con desigualdades deliberadas, tanto en el tamaño de la letra como en el número de renglones, según la importancia que da el autor (Rodríguez) a las sentencias y el empeño que tienen de hacerlas entrar por los ojos, así como también en los espacios, apartes y llaves. ${ }^{57}$

Es importante tener en cuenta que, con el descubrimiento de la realidad como sistema de signos, al menos en el campo del lenguaje y del gobierno, la semiótica adquirió en él un determinado estatuto epistemológico, que permite hablar de él como un precursor de dicha ciencia. Además, el descubrimiento de la realidad como sistema de signos testamentarios, en su gran mayoría, también lo convirtió en creador de nuevas formas de comunicación, exigidas por la cambiante situación social y en lo cual jugó un rol creativo pionero, como se puede apreciar en la organización sui géneris que supo hacer de sus escritos. Todo ello permitió a Rodríguez una praxis literaria de carácter dinámico y a su vez didáctico, bautizada con el nombre de ensayo, muy cultivado a lo largo del siglo XIX.

En fin, Extracto sucinto de 'Educación Republicana' y Consejos de amigo coronan la producción pedagógica global de Rodríguez desde Reflexiones sobre los defectos que vician la Escuela de Primeras Letras de Caracas y medio de lograr su reforma por un nuevo establecimiento, texto redactado en 1794; Sociedades Americanas, Cómo serán y como podrían ser en los siglos venideros, texto de 1828 que tuvo una segunda edición, muy ampliada, en 1842; Luces y virtudes sociales, 1834, obra que también recibió ampliaciones y reediciones y en la que se despliega como anexo, en la edición de 1840, lo referente a la Educación Popular. También, el Extracto sucinto y Consejos de amigo pueden ser vistos como una sola propuesta, $\mathrm{y}$

${ }^{57}$ Aurelio Espinosa Pólit, "Introducción a Consejos de Amigo, dados al Colegio de Latacunga" en Boletín de la Academia Nacional de Historia, V. XXXIV, No. 83, enerojunio 1954, Quito-Ecuador. 49. 
ambos a su vez están vinculados con el plan educativo de Rodríguez para Bolivia, publicado en Arequipa en 1830. Igualmente, podría establecerse vinculación con su célebre defensa de Bolívar: El Libertador del mediodía de América (enero de 1830), cuya Nota final también es 'Sobre el proyecto de Educación Popular'. ${ }^{58}$

\section{Relaciones e integración}

Túquerres y Latacunga compartieron en "aquellos tiempos" una práctica y una teoría educativa que no pierden actualidad. En la línea de continuidad que, en los contenidos y en la forma, mantiene la producción del Maestro hay una vinculación que desarrollan ambos documentos, al responder a las demandas de una región determinada o específica. Con otras palabras, la teoría pedagógica se resuelve en Extracto sucinto y Consejos de Amigo en un proyecto pedagógico específico, para dos centros educativos peculiares, en una región y tiempo determinado: Túquerres hoy instalaciones del Instituto Normal Teresiano y Latacunga: Instituto Técnico Superior Vicente León.

En relación con las amenazas de desintegración Rodríguez advertía: "Borren las divisiones territoriales de la administración Colonial, y no reconozcan otros límites que los del Océano. ¡SEAN AMIGOS SI QUIEREN SER LIBRES!". ${ }^{59}$

En la Carta de Jamaica, 6 de septiembre de 1815, Bolívar describió los vínculos de integración y de desintegración que unían y amenazaban a Hispanoamérica:

Es una idea grandiosa pretender formar de todo el nuevo mundo, una sola nacion con un solo vinculo que ligue sus partes entre sí y con el todo. Ya que tiene un origen, una lengua, unas costumbrez y una religion, deberia por consiguiente tener un solo Gobierno, que confederase los diferentes estadoz que hayan de formarse; mas no es pocible, por que climas remotos, //folio 29// situaciones diversas, intereses opuestos, caracteres de semejantes dividen á la America: ¡Que bello seria que el Ystmo de Panamá fuese para nosotros lo que el de Corinto para los Griegos.! ¡ojala que algún día tengamos la fortuna de instalar allí un augusto Congreso de los representantes de las

58 Rodríguez, Obras completas, tomo II, 355.

59 Rodríguez, Sociedades Americanas, 43. 
repúblicas, reynos é Ymperios á tratar y discutir sobre los altos intereses de la Paz y de la Guerra, con las naciones de las otras tres partes del Mundo. Esta especie de Corporacion podrá tener lugar en alguna epoca dichosa de nuestra regeneracion: otra esperanza es infundada; semejante á la del Abate Sanct. Pierre, que concibió el laudable delirio de reunir un Congreso Europeo, para desidir de la suerte y de los intereses de aquellas naciones ${ }^{60}$

Como es conocido, el sueño de Bolívar se consolidó en 1819, pero solo duró 12 años. Bolívar trabajó por la organización política de toda la América Meridional y propuso que, en cuanto Venezuela, la Nueva Granada y Ecuador se liberaran del yugo español debían formar una sola nación que se llamaría Colombia. Proyecto por el que luchó hasta su muerte en 1830.

En aquel tiempo, como lo he tratado de desplegar a lo largo de este acápite, los vínculos de unidad eran mayores a los de desintegración que se impusieron en la etapa post-independentista. Esta región constituía una unidad: sus autoridades y sus élites comerciales, educativas y religiosas se movilizaban en forma reiterada hacia la cabecera del Virreinato; sus productos viajaban y se intercambian entre una y otra provincia, su arte y su música se compartía, hasta sus comunidades indígenas se relacionaban entre sí. La zona de Pasto era un continuum espacial, económico o productivo y cultural, en las primeras décadas de la vida republicana, sin embargo, ambos países intentaron llevar Pasto a sus dominios como lo certifican la serie de enfrentamientos en que se enfrascaron las nacientes repúblicas de Colombia y Ecuador.

En definitiva, la historia fue en otra dirección. Más temprano que tarde se impusieron otras propuestas de unidad e identidad inclinadas más al campo político y al de los valores e historiografía de corte "nacional" que al social o al educativo. El traje por el que optó el país fue diferente al diseñado por Rodríguez, quien fue consciente que los tiempos no eran aún los adecuados para su plan de reforma.

Para bien nuestro, hoy se abren nuevas posibilidades de integración entre Colombia y Ecuador. Hoy por ejemplo soplan vientos a favor, pero también en contra de la unidad entre la región sur de Colombia y la del norte del Ecuador, que se ven cada día más vinculadas en medio de un contexto mundial de información y comunicación, de economía y finanzas

${ }^{60}$ Simón Bolívar. Carta de Jamaica 1815-2015, (Venezuela: Comisión Presidencial para la Conmemoración del Bicentenario de la Carta de Jamaica, 2015), 28-29. 
globales y de interrelación cultural entre ambos pueblos. Es suficiente recordar el actual intercambio comercial entre las dos naciones que crece anualmente a porcentajes sorprendentes, la ostensible mejora en sus sistemas de comunicación, sus nuevas vías carrozables, el diálogo entre las universidades de frontera, etc.

Ante los nuevos polos de desarrollo de la geopolítica mundial: Rusia; China; EE-UU; los Tigres Asiáticos: Japón, Corea del Sur, Hong Kong, Singapur y Taiwán, a los cuales se suele añadir los "tigres menores": Malasia, Indonesia, Tailandia; la Comunidad Europea que aglutina ya 28 países: Alemania, Francia, Italia, España, Bulgaria, Finlandia, Suecia... si bien esos polos, cual piezas de ajedrez se asientan sobre un tablero o piso común, compuesto básicamente por la expansión mundial de las comunicaciones y la información, el desarrollo de la ultra ciencia y la meta tecnología y la globalización de la economía y las finanzas, tendencias que se imponen en el mundo con efectos no todos positivos.

Sin embargo, en este escenario las regiones y fuerzas que comandan la geopolítica mundial también están llamadas cada vez más a superar alineamientos de carácter bipolar que caracterizó y condujo luego de la segunda guerra mundial al enfrentamiento entre Estados Unidos y la Unión Soviética por la hegemonía política, económica y militar en el mundo. Hoy, en el complejo tablero o escenario contemporáneo se abre la posibilidad de aprender a convivir bajo una geopolítica multipolar, en que los pueblos latinoamericanos aprenderán a negociar y desarrollar sus propios intereses sin la hegemonía o el menoscabo de los intereses de otras regiones.

En la última página de Consejos de Amigo, a modo de despedida, Simón Rodríguez hizo constar:

Los americanos estarían viendo el suelo que pisan, no mirando las estrellas; esperando lo que está en el orden, no que el olmo de peras; buscando su vida en el trabajo, no rezando el padre nuestro, para pedir qué almorzar; contando con lo que tienen, no con lo que les promete, el que no tiene que dar. ${ }^{61}$

${ }^{61}$ Rodríguez. Cartas, 69-70. 


\section{Conclusiones}

Estudiar el pensamiento de Simón Rodríguez es fundamental para la sociedad actual. La originalidad de sus planteamientos y de su pensamiento permite establecer las relaciones entre sus ideas y la configuración de la sociedad republicana.

Desde el ámbito educativo el diálogo que emergió entre Túquerres y Latacunga a partir de la acción y la teoría que Simón Rodríguez desplegó en uno y otro lugar fue importante para la construcción de la República en tanto permite comprender que sin un cambio educativo real no habría una sociedad justa y libre.

Los componentes de la propuesta de la educación republicana y su metodología, basados en la crítica al sistema lancasteriano, la observación, reflexión y meditación; el aprendizaje comprensivo; y las experiencias y el conocimiento significativo, además de poner en evidencia la voluntad de dar forma a una república, según Rodríguez, constituyen el único camino que garantiza la superación de los males originados por la ignorancia y mantener en pie tanto al Estado como a la República.

La reflexión sobre los aportes de Simón Rodríguez permite comprender la educación como un acto de implicaciones en la sociedad en tanto contribuyó a formar el carácter republicano, libertario; además a lo largo de sus obras quedó plasmado su ideario filosófico y pedagógico, necesario para la libertad de las sociedades americanas. Un proceso aún en construcción.

\section{Referencias}

Andrade, Roberto. Historia del Ecuador, Cuarta Parte. Quito: Corporación Editora Nacional, 1984.

Astuto Philip L., ed. Eugenio de Santa Cruz y Espejo: obra educativa, Caracas: Biblioteca de Ayacucho, 1981.

Ayala Mora, Enrique, ed. Nueva Historia del Ecuador, Vol. 7, Quito: Corporación Editora nacional-Grijalbo. 1990.

Bolívar, Simón. Carta de Jamaica 1815-2015, Venezuela: Comisión Presidencial para la Conmemoración del Bicentenario de la Carta de Jamaica, 2015. 
Borchart de Moreno, Christiana. Llamas y ovejas: El desarrollo del ganado lanar en la Audiencia de Quito. En: Escobari de Querejazu, Laura -coord. Colonización agrícola y ganadera en América, siglos XVI-XVIII: su impacto en la población aborigen, Quito: Ediciones Abya-Yala, 1995.

Büschges Christian, Familia, honor y poder. La nobleza quiteña de Quito en la época colonial tardía (1765-1822), Quito: Trama, 2007.

Colom Antoni J. y Lélich Joan Carles. Después de la Modernidad, Nuevas filosofías de la educación, Barcelona: Paidós, 1994.

Egred A. José. El terremoto de Riobamba de febrero de 1797. Tomo 2, Quito: Ed. Abya-Yala, 2000.

Espejo, Eugenio. Primicias de la Cultura de Quito, Quito: Publicación del Archivo Municipal, 1947.

Espinosa Pólit, Aurelio. "Introducción a Consejos de Amigo, dados al Colegio de Latacunga" en Boletín de la Academia Nacional de Historia, V. XXXIV, No. 83, Enero-Junio 1954, Quito-Ecuador. 49.

Granda Paz, Osvaldo, Pintor y soldado en la Independencia. Ecuador-Colombia, Ed. Morada, 2017.

Granda Paz, Osvaldo. "Antecedentes de la propuesta de educación popular de Don Simón Rodríguez". Revista Historia de la Educación Colombiana, 14 (14), (2011), 9-29. Disponible en: https://revistas.udenar.edu.co/index.php/ rhec/article/view/564.

Granda Paz, Osvaldo. "Las primeras letras en Quito (1791-1850)". Tesis de doctorado en Ciencias de la Educación, CADE Universidad de NariñoRUDECOLOMBIA, 2014.

Granda Paz, Osvaldo. "Mora Berbeo y la Enseñanza Mutua en la Gran Colombia". Revista Historia De La Educación Colombiana 19 (19), (2016), 81-105. Disponible en: https://doi.org/10.22267/rhec.161919.16.

Guerrero Vinueza, Gerardo León. Pasto en la Guerra de la Independencia: 18091824. (Bogotá, Ed. Tecnimpresores, 1994. 
Lasheras, Jesús Andrés. "Ensayo: Simón Rodríguez en sus cartas", Simón Rodríguez Cartas, Caracas: Ediciones Rectorado-Universidad Nacional Experimental Simón Rodríguez, 2001.

Moncayo y Esparza, Pedro. El Ecuador de 1825 a 1875. Quito: Imprenta Nacional, 1907.

Muñoz Cordero, Lydia Inés. El Gobierno Autónomo de Quito en 1809, Repercusiones en la Independencia de la Nueva Granada, Quito: Ed. Academia Nacional de Historia del Ecuador, 2018.

Núñez, Jorge. "Inicios de la educación pública en el Ecuador", Procesos Revista ecuatoriana de historia, 13 (13), (2015), 3-23. DOI:10.29078/rp.v1i13.329

Rodríguez, Simón. "Extracto sucinto sobre la educación republicana", NeoGranadino, Nos. 39, 40 y 42, Bogotá, mayo de 1849.

Rodríguez, Simón. Extracto sucinto de mi obra sobre la educación republicana, Austin: Fondo Editorial J. A. Segrestáa, Universidad de Texas, 1969.

Rodríguez, Simón. Sociedades Americanas, Caracas: Biblioteca Ayacucho, 1990.

Rodríguez, Simón. Obras Completas, tomo I y II, Caracas: Ediciones RectoradoUniversidad Simón Rodríguez, 2016.

Sarmiento, Domingo Faustino. Facundo o Civilización y Barbarie, Buenos Aires: Biblioteca del Congreso de la Nación, 2018.

Tapia Tamayo, Amílcar. El pupo: visión histórica, Tulcán: Ed. Parlamento Andino, 2003.

Wolf, Teodoro. Crónica de los fenómenos volcánicos y terremotos en el Ecuador. Con algunas noticias sobre otros Países de la América Central y Meridional desde 1599 hasta 1797. Quito: Imprenta de la Universidad Central, 1904.

\section{Citar este artículo}

Paladines Escudero, Carlos Augusto. "Simón Rodríguez y la educación republicana: relaciones entre el sur de Colombia-Túquerres y el norte de EcuadorLatacunga". Revista Historia de la Educación Colombiana. Vol. 25 No 25 (2020): 15-54. DOI: https://doi.org/10.22267/rhec.202525.82 